\section{Evaluation of Absorption Process for Heavy Metals Removal found in Pharmaceutical Wastewater}

\section{Abstract}

This study focused on the adsorption/absorption process of natural volcanic tuff, its application, kinetics, efficiency, velocity and selectivity order in removing heavy metals found in pharmaceutical wastewater.

Series of experiments were conducted in batch-wise and fixed-bed columns to study the removal performance and selectivity sequence of mixed metal ions $\left(\mathrm{Pb}^{2+}\right.$, $\mathrm{Cr}^{6+}, \mathrm{Cu}^{2+}, \mathrm{Zn}^{2+}$ and $\mathrm{Fe}^{3+}$ ) in aqueous solution using natural volcanic tuff material as adsorbent. The main purpose of this study is to highlight the economical application of the method in treatment of pharmaceutical wastewater.

Heavy metal salts were used to prepare synthetic pharmaceutical wastewater containing a mixture of different metal ions concentrations ranged from 1 to 20 $\mathrm{mg} / \mathrm{L}$ were to be applied to columns packed with natural volcanic tuff rich in zeolite ranged between $(0.50-3.50 \mathrm{~mm})$ in grain size. Photometric procedure was used for sample analysis. The absorption experiments were carried out under changing conditions, different $\mathrm{pH}$-values $(2,4,6$ and 7$)$, initial solute concentrations $(1,5$ and 10$) \mathrm{mg} / \mathrm{L}$, different temperatures $\left(10,20\right.$ and $\left.30^{\circ} \mathrm{C}\right)$ and varying tuff particle sizes $(0.50-3.50) \mathrm{mm}$.

The results showed that Freundlich model described satisfactorily sorption of $\mathrm{Cu}^{2+}$ and $\mathrm{Fe}^{2+}$. Used volcanic tuff exhibit efficiency in removing heavy metals ranging from $45-99 \%$ of the added $\mathrm{Cr}, \mathrm{Cu}, \mathrm{Zn}, \mathrm{Pb}$ and Fe metal concentrations, respectively. According to the percentage sorption and distribution coefficients values, the selectivity sequence of studied metals by volcanic tuff is strongly dependent of $\mathrm{pH}$, however approximating all results a selectivity sequence can be given as $\mathrm{Pb}$ $\geq \mathrm{Fe}>\mathrm{Cr}>\mathrm{Zn}>\mathrm{Cu}$ at $\mathrm{pH}$ around 2 and a selectivity sequence as $\mathrm{Fe}>\mathrm{Cu}>\mathrm{Cr}>\mathrm{Zn}>\mathrm{Pb}$ at $\mathrm{pH}=6-7$. The result confirms that natural volcanic tuff hold great potential to remove cationic heavy metal species from industrial wastewater.

Keywords: Heavy metal ions; Absorption; Pharmaceutical wastewater; Natural volcanic tuff

\section{Jamal A Radaideh ${ }^{1 *}$, Hassan Al Abdulgader ${ }^{2}$ and Matthias Barjenbruch ${ }^{3}$}

\author{
1 Civil and Environmental Engineering \\ Department, Al Balqa Applied University, \\ Jordan \\ 2 King Faisal University, Saudi Arabia \\ 3 FG Urban Water Management, Berlin, \\ Geramny
}

\section{*Corresponding author: Jamal A Radaideh \\ ” jalradaideh@kfu.edu.sa}

Civil and Environmental Engineering Department, Al Balqa Applied University, Jordan.

Tel: 00962777487350

Citation: Radaideh JA, Abdulgader HA, Barjenbruch M (2017) Evaluation of Absorption Process for Heavy Metals Removal found in Pharmaceutical Wastewater. J Med Toxicol Clin Forensic Med Vol.3 No.2:9

Received: September 15, 2017; Accepted: September 30, 2017; Published: October 07,2017

\section{Introduction}

Effluents from various processing industries and other utilities such as electroplating industries, medical care centers and hospitals is reported to contain high amounts of heavy metal ions, such as nickel, iron, lead, zinc, chromium, cadmium and copper [1]. Heavy metals are naturally occurring elements and the multiple industrial, domestic, agricultural, medical and technological applications have led to their wide distribution in the environment; raising concerns over their potential effects on human health and the environment. Their toxicity depends on several factors including the dose, route of exposure and chemical species, as well as the age, gender, genetics, and nutritional status of exposed individuals. For this reason, heavy metals and their toxicity to environment is being the subject for many studies [2-7]. Due to mutagenic and carcinogenic properties 
of heavy metals, much attention has been paid for occurrence, concentrations, movement, fate and the anticipated health and environmental risks that may arise from these heavy metals since they have direct exposure to humans and other organisms $[8,9]$. The demand for pharmaceuticals has resulted in a consequent increase in pharmaceutical manufacturing companies in the world and hence increased pharmaceutical waste which most times contain substantial amount of heavy metals. Pharmaceutical residues in the environment, and their potential toxic effects, have been recognized as one of the emerging research area in the environmental chemistry $[10,11]$. Pharmaceutical effluents are usually discharged into the environment and when improperly handled and disposed, they affect both human health and the environment $[12,13]$.

The presence of pharmaceutical compounds in waters comes from two different sources: production processes of the pharmaceutical industry and common use of pharmaceutical compounds resulting in their presence in urban wastewaters [14-17]. The pharmaceutical wastewaters generated in different processes in the manufacture of pharmaceuticals and drugs contain a wide variety of dangerous compounds including heavy metals [18]. Further, reuse of water after removal of contaminants, whether pharmaceuticals or otherwise, is required by industry and agriculture. In view of the scarcity of water resources, it is necessary to understand and develop methodologies for treatment of pharmaceutical wastewater as part of water management.

In order to remove toxic heavy metals from water systems, conventional methods have been used such as chemical precipitation, coagulation, ion exchange, solvent extraction and filtration, evaporation and membrane methods [19]. These conventional treatment technologies for the removal of these toxic heavy metals are not efficient and generate huge quantity of toxic sludge. Adsorption of heavy metals on conventional adsorbents such as activated carbon have been used widely in many applications as an effective adsorbent and the activated carbon produced by carbonizing organic materials is the most widely used adsorbent. However, the high cost of the activation process limits its use in wastewater treatment applications [20].

Bio-sorption using natural materials locally available in certain regions is emerging as a potential alternative to the existing conventional technologies for the removal and/or recovery of metal ions from aqueous solutions. Low cost and availability, high metal binding capacity, minimum production of chemical or biological sludge, possible regeneration of bio-sorbents count for the major advantages of using bio-sorption methodology over conventional treatment methods.

Zeolite-based technology can provide a cost effective solution for pharmaceutical wastewater treatment for the removal of toxic heavy metals under increasing demand of safe water from alternative sources [21-23]. Numerous previous studies have investigated the removal efficiency of zeolite tuff when placed in fixed bed columns confirmed their excellent performance on the removal of metal cations from wastewaters [24-26].
The efficiency of water treatment by using natural and modified zeolites depends on the type and quantity of the used zeolite, the size distribution of zeolite particles, the initial concentration of contaminants (cation/anion), $\mathrm{pH}$ value of solution, ionic strength of solution, temperature, pressure, contact time of system zeolite/solution and the presence of other organic compounds and anions. For water treatment with natural zeolites, standard procedures are used, usually a procedure in column or batch process. Ion exchange and adsorption properties of natural zeolites in comparison with other chemical and biological processes have the advantage of removing impurities also at relatively low concentrations and allows conservation of water chemistry, if the treatment is carried out in the column process [27-30].

There are several regions lacking water resources and this necessitates that much effort is put into water conservation and environmental protection. The expansion of industrial activities, including metal-based industries, and the excessive use of chemicals enhance the pollution of waters with heavy metals. All these require the availability of low-cost technology and materials for wastewater treatment. However, volcanic tuff deposits, rich in phillipsite and zeolite are natural occurring deposits, which they can be found in huge reserves in many regions [31].

In this study, the sorption behavior of natural occurring volcanic tuff rich in zeolite with respect to chromium $(\mathrm{Cr})$, copper ( $\mathrm{Cu})$, lead $(\mathrm{Pb})$, zinc $(\mathrm{Zn})$ and iron (Fe) ions has been thoroughly examined to confirm its performance for application to purify industrial wastewaters. The batch method has been employed, using competitive sorption system with metal concentrations in solution ranging from 1-20 mg/l. Parameters such as $\mathrm{pH}$, contact time, and initial metal concentration, were considered. The equilibrium adsorption capacity of volcanic tuff for studied heavy metals was measured and extrapolated using linear Freundlich and Langmuir isotherms. The results indicate the potentially practical value of this method in industries and also provide strong evidence to support the adsorption mechanism proposed.

The present research work aims to study the adsorption/ adsorption behavior of different heavy metal ions $\mathrm{Cr}^{6+}, \mathrm{Pb}^{2+}, \mathrm{Zn}^{2+}$, $\mathrm{Cu}^{2+}$ and $\mathrm{Fe}^{2+}$ at natural untreated volcanic tuff material. The results showed that Freundlich model described satisfactorily sorption of all metals. Used volcanic tuff exhibit efficiency in removing heavy metals ranging from $45-99 \%$ of the added $\mathrm{Cr}, \mathrm{Cu}$, $\mathrm{Zn}, \mathrm{Pb}$ and $\mathrm{Fe}$ metal concentrations, respectively. According to the percentage sorption and distribution coefficients values, the selectivity sequence of studied metals by volcanic tuff is strongly dependent of $\mathrm{pH}$, however approximating all results a selectivity sequence can be given as $\mathrm{Pb} \geq \mathrm{Fe}>\mathrm{Cr}>\mathrm{Zn}>\mathrm{Cu}$ at $\mathrm{pH}$ around 2 and a selectivity sequence as $\mathrm{Fe}>\mathrm{Cu}>\mathrm{Cr}>\mathrm{Zn}>\mathrm{Pb}$ at $\mathrm{pH}=6-7$. The results show that natural volcanic tuff hold great potential to remove cationic heavy metal species from industrial wastewater.

\section{Materials and Methods}

\section{Glass columns}

Glass columns with different heights $(40-70 \mathrm{~cm}$, and $\Phi 5 \mathrm{~cm})$ were used in the batch and column experiments. As pack and 
ion exchanger material, Jordanian natural tuff grains were used. Continuous flow fixed-bed column was applied to study the efficiency of the tuff bed rich in zeolite in removing heavy metal ions from pharmaceutical wastewater. The operation was controlled through the variables (flow rate, bed depth, and column internal diameter).

\section{Absorbent}

Natural occurring and untreated volcanic tuff rich in zeolite is used as absorbent. The conventional mineral processing techniques of tuff are starting with crushing the materials followed by autogenously tumbling mill and then low intensity magnetic and gravity separation. The crushed original tuff was ground and passed through 4-0.5 $\mathrm{mm}$ sieves and was dried in an oven at $104.5^{\circ} \mathrm{C}$ for $24 \mathrm{~h}$.

The absorbent grains undergo a chemical treatment to eliminate any biological and oxidizable contents, batches of $50 \mathrm{~g}$ of reagents were boiled separately with $50 \mathrm{~mL}$ of $\mathrm{HCL}$ acid or $\mathrm{H}_{2} \mathrm{SO}_{4}$ acid with concentration of $0.1 \mathrm{M}$ or $1.0 \mathrm{M}$ for $30 \mathrm{~min}$ to destroy organic matter [32], then filtered under vacuum and washed thoroughly with distilled water until a $\mathrm{pH}$ of 7 is maintained. The acidified reagents were dried overnight at $80^{\circ} \mathrm{C}$. Volcanic tuff was grounded and then passed through 4-0.5 $\mathrm{mm}$ sieves and dried in an oven at $104.5^{\circ} \mathrm{C}$ for $24 \mathrm{~h}$.

The grain size distribution of the used volcanic tuff is presented in Table 1.

The tuff was not exposed to any pre-treatment or modification. Samples were just washed and dried at $103.5^{\circ} \mathrm{C}$ and kept in desiccators for $24 \mathrm{~h}$ to ensure complete drying out.

\section{Absorbate}

The initial aqueous solution concentrations of absorbate $(1,5$, 10 and 20) $\mathrm{mg} / \mathrm{L}$ were prepared using standard solutions for each metal. Standard solutions of metal chlorides of $500 \mathrm{mg} / \mathrm{l}$ and $1000 \mathrm{~mL}$ were used as adsorbate. Solutions of various concentrations were obtained by diluting the standard solution with distilled water.

Chromium stock solution (100 ppm) was prepared by dissolve $0.1923 \mathrm{~g}$ of chromium (VI) oxide $\left(\mathrm{CrO}_{3}\right)$ in water. When solution is complete, acidification with $10 \mathrm{~mL}$ concentrated nitric acid and dilute to $1000 \mathrm{~mL}$ with water $(1.00 \mathrm{~mL}=100 \mu \mathrm{g} \mathrm{Cr})$. The stock solutions of copper, lead and zinc were prepared by dissolving $2.1368 \mathrm{~g}$ of copper chloride, $1.3557 \mathrm{~g}$ of lead chloride and 2.1237 $\mathrm{g}$ of zinc chloride in $1000 \mathrm{~mL}$ volumetric flasks, respectively. A stock solution for iron was prepared by adding $7.3073 \mathrm{~g}$ of $\mathrm{Fe}\left(\mathrm{NO}_{3}\right)_{3}$ in a $1000 \mathrm{ml}$ volumetric flask.

Table 1 The grain size distribution of used aggregates.

\begin{tabular}{|c|c|c|}
\hline Weight $(\mathrm{g})$ & Grain size $(\mathrm{mm})$ & Percentage $(\%)$ \\
\hline 1000 & $\leq 4$ & 100 \\
\hline 414.3 & $\geq 3$ & 41.4 \\
\hline 309.1 & $\geq 2$ & 30.9 \\
\hline 211.5 & $\geq 1$ & 21.1 \\
\hline 65.1 & $\geq 0.5$ & 6.5 \\
\hline
\end{tabular}

Heavy metal concentrations were determined by spectrophotometer. All the chemicals used were of analytical grade reagent and all experiments were carried out in $500 \mathrm{ml}$ glass bottles at the laboratory ambient temperature of $25 \pm 2^{\circ} \mathrm{C}$.

\section{Characterization and identification of absorbent (natural volcanic tuff material)}

Representative samples of used volcanic tuff were investigated by using optical microscopy, scanning electron microscopy (SEM), $X$-Rays diffraction (XRD).

The instrument used is a Philips XL30 FEGSEM with Oxford CT1500HF Cryo stage and EDAX DX4 integrated Energy Dispersive $X$-ray Analyzer. Micro-structural and elemental constituents are imaged and analyzed with magnifications up to 50,000; i.e., image clarity at $<200 \mathrm{~nm}$ (nanometers) scale. The X-ray diffraction analysis indicated that the examined raw tuff material is rich in zeolite beside other non-zeolite materials.

The bulk chemical composition of volcanic tuff was measured using XRD; the data for chemical composition of the used fractions are given in Table 2 . The main components were $\mathrm{SiO}_{2}$, $\mathrm{Al}_{2} \mathrm{O}_{3}$ and $\mathrm{Fe}_{2} \mathrm{O}_{3}$ with others found in low concentrations.

Figures 1 and $\mathbf{2}$ shows an energy dispersive X-ray spectroscopy (EDS, EDX or EDXRF) for the used tuff crystals. It is an analytical technique used for the elemental analysis of a sample.

Scanning electron microscope (SEM) as shown in Figure 3, illustrates that the tuff material exhibit significant surface area with a large number of holes and pores, layers and sheets which allow water to pass through and due to the high surface area, the adsorption process will be promoted to occur quickly and easily. Its characterization capabilities are due in large part to the fundamental principle that each element has a unique atomic structure allowing $x$-rays that are characteristic of an element's

Table 2 Chemical composition and physical properties of natural tuff sample (wt \%).

\begin{tabular}{|c|c|c|c|}
\hline Compound & Weight \% & Compound & Weight \% \\
\hline $\mathrm{SiO}_{2}$ & 65.18 & $\mathrm{MnO}$ & 0.44 \\
\hline $\mathrm{Al}_{2} \mathrm{O}_{3}$ & 12.24 & $\mathrm{Na}_{2} \mathrm{O}$ & 1.55 \\
\hline $\mathrm{CaO}$ & 3.18 & $\mathrm{~K}_{2} \mathrm{O}$ & 3.78 \\
\hline $\mathrm{MgO}$ & 1.96 & $\mathrm{TiO}_{2}$ & 0.26 \\
\hline $\mathrm{Fe}_{2} \mathrm{O}_{3}$ & 1.2 & $\mathrm{SO}_{3}$ & 0.23 \\
\hline
\end{tabular}

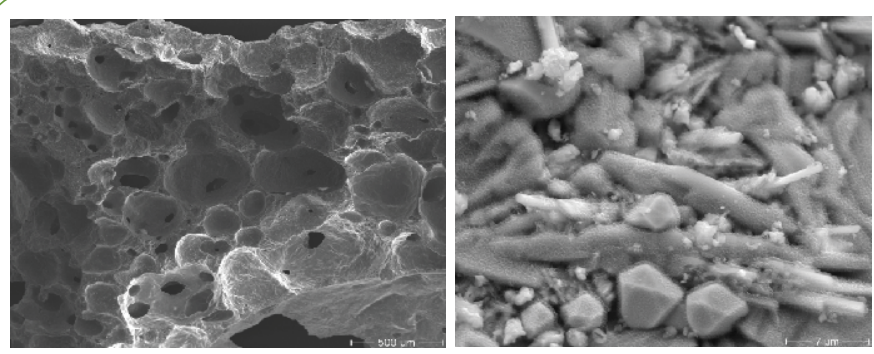

Figure 1

SEM images of used zeolite tuff shows tabular crystals associated with small fibrous crystals. 

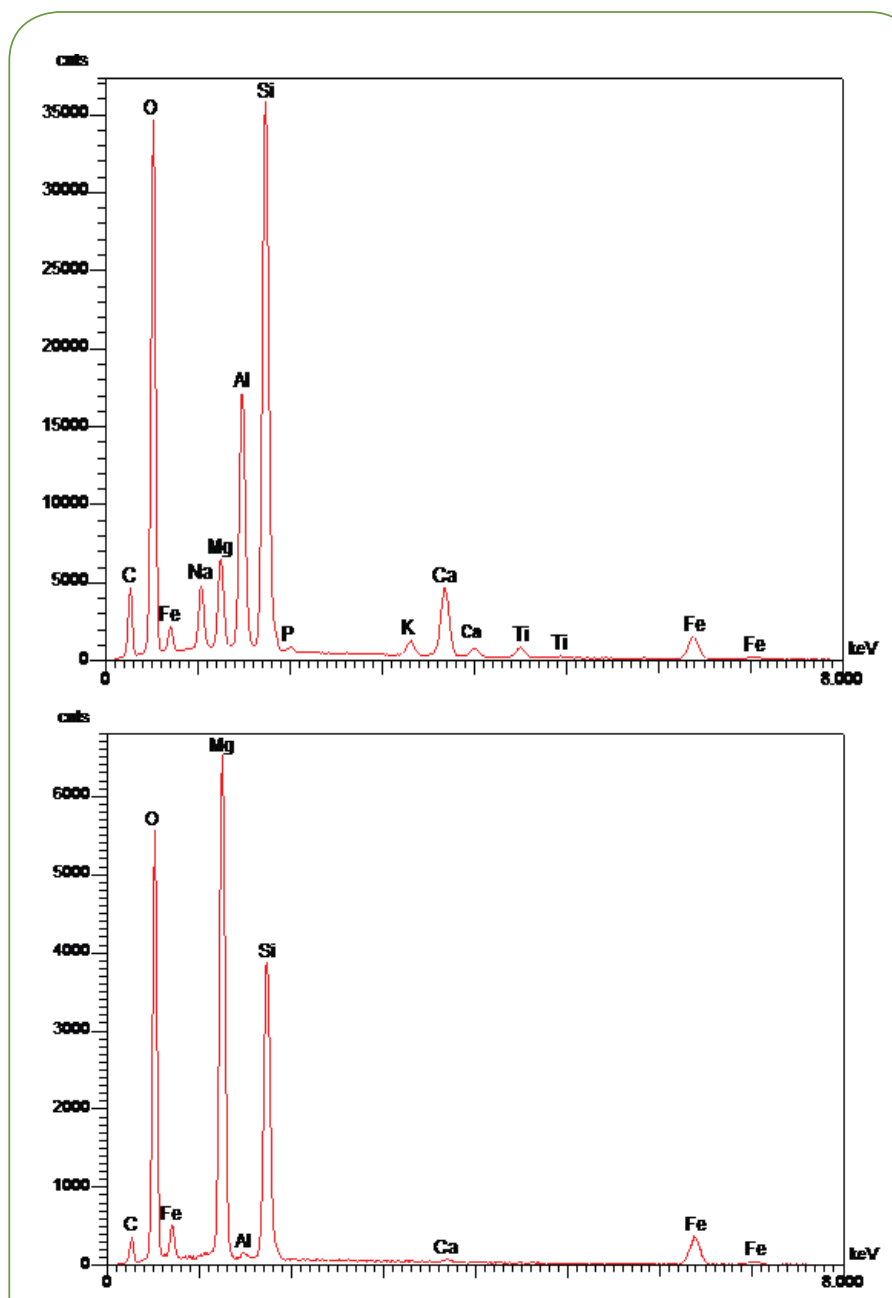

Figure 2 X-Rays diffraction spectrum of the used zeolite tuff.

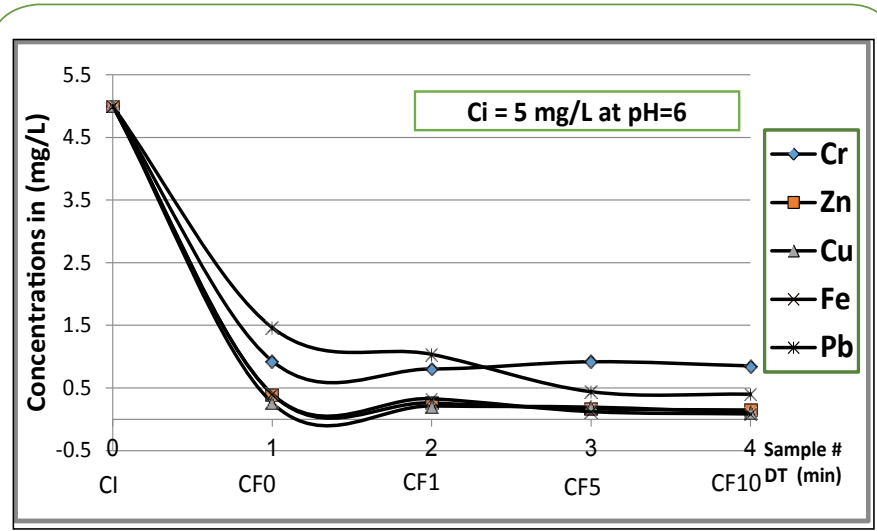

Figure 3 Effect of contact time on the removal of heavy metals on volcanic tuff grains.

atomic structure to be identified uniquely from each other. Identification of the principal elements; C, O, Fe, $\mathrm{Na}, \mathrm{Mg}, \mathrm{Al}$, $\mathrm{Si}, \mathrm{Ca}, \mathrm{P}, \mathrm{K}, \mathrm{Ti}$. The presence of these elements give the tuff the property of being an excellent ion exchanger.

The structures of volcanic tuff consist of three-dimensional frameworks of $\mathrm{SiO}_{4}^{+}$and $\mathrm{AlO}_{4}^{+}$tetrahedral. They were characterized by X-ray diffraction (XRD) and chemical analysis
[33]. $\mathrm{Al}_{2} \mathrm{O}_{3}, \mathrm{Fe}_{2} \mathrm{O}_{3}, \mathrm{CaO}$, and $\mathrm{MgO}$ were analyzed using titrimetric methods and $\mathrm{SiO}_{2}$ was analyzed with a gravimetric method. $\mathrm{Na} 2 \mathrm{O}$ and $\mathrm{K} 2 \mathrm{O}$ were found by flame photometry. The results of chemical analysis are presented in Table 2.

\section{Adsorption Experiments}

\section{Design of experiments}

In the present work, a batch-scale system using coarse and fine zeolite tuff packed columns was operated to investigate the continuous removal of heavy metals. In these experiments, the effects of flow rate, contact time, particle size, column height, initial solute concentration, $\mathrm{pH}$ and temperature on removal efficiency were investigated.

In one-dimensional experiments with volcanic tuff aggregates filled columns of different sizes (fine, middle and coarse size), were fed with aqueous solution having different initial concentrations from top. The fixed bed columns, which will allow the most experimental variations, are to be filled with a layer of fine grains $<1 \mathrm{~mm}$ at the bottom, over which a layer of tuff (different grain sizes) comes to slow down water passage. The hydraulic conductivity can be controlled by recording the time required to collect the injected sample outflow (contact time). Samples from inflow and outflows should be taken for chemical analyses, whereas zeolite tuff samples are to be taken for analyzing to record changes in chemical composition.

Synthetic wastewater samples were prepared to give heavy metal solutions with concentrations of $1 \mathrm{mg} / \mathrm{L}, 5 \mathrm{mg} / \mathrm{L}, 10 \mathrm{mg} / \mathrm{L}$ and $20 \mathrm{mg} / \mathrm{L}$ by adding an appropriate standard solutions to deionized water.

The dry mass of volcanic tuff used in one column is about $79.52 \mathrm{~g}$ which forms a height of $10 \mathrm{~cm}$. The volume of wastewater sample applied in the columns each run is $40 \mathrm{ml}$.

\section{Sampling procedure}

The uptake of metal ions by tuff material was studied to assess and understand the maximum removal efficiency under considering changing experimental variables. For these investigations, several $50 \mathrm{~mL}$ glass test tubes were used. Each test tube received $40 \mathrm{~mL}$ of a metal ion solution (each run has different initial concentration) and adjusted to the desired $\mathrm{pH}$ from 2.0 to 7.0 and controlled using a $\mathrm{pH}$ meter. The $\mathrm{pH}$ of the solution was adjusted using dilute solution of $0.1 \mathrm{~N}$ hydrochloric acid $\mathrm{HCl}$ or sodium hydroxide $\mathrm{NaOH}$ as necessary. Each test tube is filled with fixed amount of volcanic tuff $(10 \mathrm{mg})$. The solution was introduced at a constant volumetric flow rate $(Q=40 \mathrm{~mL})$ and initial concentration (Ci).

A continuous shake of tubes were performed to maintain equilibrium and complete mixing. The effluent suspension was diluted (if necessary) to an appropriate concentration range and filtered through Whatman filter paper for the elemental analysis by atomic absorption spectroscopy (A.A.S). The contact time denoted as CT in minutes which reflects the real detention time of the aqueous solution within the fixed bed. Each batch consists of 4 effluent samples with detention times varying from 
zero to 10 minutes. The first sample (sample \# 1) is added to fixed bed and collected immediately at the bottom, practically with a detention time zero (CFO). The second sample (sample \# 2 ) is collected after lasting in the bed for $1 \mathrm{~min}$ (CF1), the third sample (sample \# 3) lasts $5 \mathrm{~min}$ (CF5), while the fourth sample (sample \# 4) is allowed to last $10 \mathrm{~min}$ (CF10) within the bed prior to discharge. The experiment was conducted under a controlled room temperature (Air Conditioning unit controlled the temperature) in order to make the working temperature constant at $25^{\circ} \mathrm{C}$ for a predetermined time $(24 \mathrm{~h})$ with continuous stirring. A peristaltic pump every 10 min feeds the column with $40 \mathrm{~mL}$ of aqueous solution. The small aliquots of samples were withdrawn from the reaction.

Experimental data were used to determine the equilibrium time, equilibrium concentrations, amounts adsorbed at equilibrium, optimum initial $\mathrm{pH}$ and temperature influence over the biosorption process. Preferable removal sequence series were obtained. Also the experimental data were used to establish isotherm (linear and nonlinear regression), kinetics models and to calculate thermodynamic parameters. All the experiments were repeated three times, the values presented were calculated using averaged concentration readings.

\section{Results and Discussion}

In experimental performance by the batch method, due to the small ratio of volumes of volcanic tuff/solution, the kinetics of the removal is determined by diffusion through the natural volcanic tuff particles. The experiments are carried out at different $\mathrm{pH}$ values $(2,4,6$ and 7$)$ and with different initial concentrations ( $1 \mathrm{mg} / \mathrm{L}, 5 \mathrm{mg} / \mathrm{L}$ and $10 \mathrm{mg} / \mathrm{L}$ ). The results show that the ionic exchange reactions took place for all samples in the experiments. The most obvious result obtained for all metals is the observed decrease in the initial concentration indicating that volcanic tuff is an active material in the absorption/ionic exchange process and can be used with high efficiency for removal of heavy metals from aquatic solutions.

In addition, a fundamental finding is that the heavy metal ions uptake is mainly correlated to solution $\mathrm{pH}$, also that the removal of heavy metals is selective and selectivity order for removal could be established.

\section{Effect of pH on metal uptake, efficiency and selectivity sequence}

Ambient $\mathrm{pH}$ was likely to be a major factor in the quantity of metal ion bio-adsorption owing to cations competition effects with hydrogen ions. Solution $\mathrm{pH}$ has a significant impact on heavy metal removal by zeolitic tuff since it can influence metal speciation, integrity of zeolite (mineral's surface properties) and also $\mathrm{H}^{+}$ions are considered competitive in ion exchange [2,3437]. $\mathrm{pH}$ is one of the most important parameters influencing not only site dissociation, but also the solution chemistry of the heavy metals since hydrolysis, complexation by organic and/or inorganic ligands, precipitation and availability of heavy metals are all influenced by it [38]. In this study, the adsorption capability of the volcanic tuff was observed to be strongly influenced by
$\mathrm{pH}$ change. The experiments and obtained results exhibit clearly the decrease in initial concentrations of metal ions as a direct function of $\mathrm{pH}$.

Table 3 represents the obtained results regarding the preferable uptake sequence of heavy metals in association with $\mathrm{pH}$. It illustrates a summary of the optimal $\mathrm{pH}$ scale by which the highest uptake rate of each metal is occurring. In addition, it demonstrates the removal efficiency for each metal in correlation with the contact time between metal ions and tuff particles. For instance, at $\mathrm{pH} \mathrm{4}$, adsorption percentage was 73.3\% for $\mathrm{Cr}$, 95.7\% for $\mathrm{Fe}, 97 \%$ for $\mathrm{Cu}, 89 \%$ for $\mathrm{Zi}$ and $95 \%$ for $\mathrm{Pb}$. At $\mathrm{pH} 6$, the corresponding values rose to $83 \%, 98 \%, 98 \%$, $97 \%$ for $\mathrm{Cr}, \mathrm{Fe}, \mathrm{Cu}$ and $\mathrm{Zi}$, respectively, but decreased to $92 \%$ for lead. These results are similar to results reported by $[39,40]$ for heavy metal ions sorption onto agricultural waste sorbents. Obtained results of this study revealed that adsorption efficiency of volcanic tuff is optimum at $\mathrm{pH} 4$ to $\mathrm{pH}$ 7. Low adsorption rates of metal ions at higher $\mathrm{pH}>7$ could be attributed to the formation of their hydroxides which build precipitate and prevent further adsorption as suggested by Lisa et al. [41], Xiao and Ju-Chang [42] and Olayinka et al. [43].

In similar studies the use of natural and modified zeolites has been further examined for the simultaneous removal of $\mathrm{Fe}^{+2}$ and $\mathrm{Mn}^{+2}$ from underground water samples and results of $\mathrm{Fe}^{+2}$ and $\mathrm{Mn}^{+2}$ removal levels were suggested to be between $22-90 \%$ and $61-100 \%$ for natural zeolite - clinoptilolite [42]. In addition several selectivity sequences have been reported in several similar adsorption studies (mainly conducted in a single solution) for natural zeolites [25]: $\mathrm{Co}^{2+}>\mathrm{Cu}^{2+}>\mathrm{Zn}^{2+}>\mathrm{Mn}^{2+}$. The selectivity series of clinoptilolite in the sodium form was determined by Olayinka et al. [43] as follows: $\mathrm{Pb}^{+2}>\mathrm{Cd}^{2+}>\mathrm{Cs}^{+}>\mathrm{Cu}^{2+}>\mathrm{CO}^{2+}>\mathrm{Cr}^{3+}>\mathrm{Zn}$ ${ }^{2+}>\mathrm{Ni}^{2+}>\mathrm{Hg}^{2+}$.

The removal efficiency for each heavy metal $(\mathrm{Cr}, \mathrm{Zn}, \mathrm{Cu}, \mathrm{Fe}$ and $\mathrm{Pb})$ was calculated in relation to different acidic conditions $(\mathrm{pH}=2$, 4, 6 and 7) with respect to initial solute concentration $\mathrm{Ci}$ (1, 5 and $10 \mathrm{mg} / \mathrm{L}$ ). As result of absorption analysis, huge data sets were obtained (Tables 3 and 4). which describe the absorption/ adsorption process of heavy metals on absorbent in relation to $\mathrm{pH}$ of solution, contact time and the initial concentration of solute used. Based on data obtained, it is to confirm that the absorbent behaves differently in regard to absorbing heavy metal ions in relation to $\mathrm{pH}$, contact time and the initial concentrations of ions applied. Figure 4 shows the removal efficiency of investigated heavy metals in relation to contact time time (CF0 to CF10) when applied to absorbent with an initial concentration of $10 \mathrm{mg} / \mathrm{L}$ at $\mathrm{pH}=2$. It is clearly demonstrated that at these predefined conditions volcanic tuff has great affinity to absorb iron ions followed by lead and chromium. As presented in Tables 3 and 4, when one or more of these prior defined experimental conditions change, the affinity and abundance of tuff material to absorb metals varies, sometimes significantly.

\section{Removal efficiency}

The removal efficiency was calculated using the equation:

Removal efficiency $=(\mathrm{Ci}-\mathrm{Cf}) / \mathrm{Ci} \times 100 \%$ which exactly reflects the percent of adsorption/absorption 
Table 3 Preferable removal sequence (selectivity order series) of heavy metals and the efficiency of removal for each element in relation to $\mathrm{pH}$ and initial concentrations.

\begin{tabular}{|c|c|c|c|c|c|c|c|}
\hline \multirow{2}{*}{ pH } & \multirow{2}{*}{$\underset{(\mathrm{mg} / \mathrm{l})}{\mathrm{Ci}}$} & \multirow{2}{*}{$\begin{array}{c}\text { Preferable } \\
\text { removal sequence }\end{array}$} & \multicolumn{5}{|c|}{ Removal efficiency* (\%) } \\
\hline & & & $\mathrm{Cr}$ & Fe & $\mathrm{Cu}$ & $\mathrm{Zn}$ & $\mathrm{Pb}$ \\
\hline & 1 & $\mathrm{~Pb}>\mathrm{Fe}>\mathrm{Cr}>\mathrm{Cu}>\mathrm{Zn}$ & 69.6 & 98.2 & 57 & 10 & 98 \\
\hline \multirow[t]{3}{*}{2} & 5 & $\mathrm{~Pb} \geq \mathrm{Fe}>\mathrm{Cr}>\mathrm{Zn}>\mathrm{Cu}$ & 91 & 92.4 & 48.8 & 51.0 & 95.6 \\
\hline & 10 & $\mathrm{Fe}>\mathrm{Pb}>\mathrm{Cr}>\mathrm{Cu}>\mathrm{Zn}$ & 85.5 & 95.4 & 51.2 & 40.2 & 96.7 \\
\hline & 1 & $\mathrm{Cu}>\mathrm{Pb}>\mathrm{Cr}>\mathrm{Fe}>\mathrm{Zn}$ & 91.9 & 97.2 & 98.5 & 58 & 98 \\
\hline \multirow[t]{3}{*}{4} & 5 & $\mathrm{~Pb}>\mathrm{Cu}>\mathrm{Zn}>\mathrm{Cr}>\mathrm{Fe}$ & 88.1 & 88.0 & 98 & 96 & 99 \\
\hline & 10 & $\mathrm{Fe}>\mathrm{Cu}>\mathrm{Pb}>\mathrm{Zn}>\mathrm{Cr}$ & 73.3 & 95.7 & 97 & 89 & 95 \\
\hline & 1 & $\mathrm{Cu}>\mathrm{Fe}>\mathrm{Pb}>\mathrm{Cr}>\mathrm{Zn}$ & 90 & 98 & 99 & 71.6 & 97 \\
\hline \multirow[t]{3}{*}{6} & 5 & $\mathrm{Cu}>\mathrm{Zn}>\mathrm{Fe}>\mathrm{Cr}>\mathrm{Pb}$ & 83 & 98 & 98 & 97 & 92 \\
\hline & 10 & $\mathrm{Fe}>\mathrm{Cu}>\mathrm{Cr}>\mathrm{Zn}>\mathrm{Pb}$ & 73 & 99 & 99 & 95 & 88 \\
\hline & 1 & $\mathrm{Fe}>\mathrm{Cu}>\mathrm{Cr}>\mathrm{Zn}>\mathrm{Pb}$ & 86 & 99 & 91 & 67 & 93 \\
\hline \multirow[t]{2}{*}{7} & 5 & $\mathrm{Cu}>\mathrm{Fe}>\mathrm{Pb}>\mathrm{Cr}>\mathrm{Zn}$ & 90 & 97 & 97 & 71 & 94 \\
\hline & 10 & $\mathrm{Fe}>\mathrm{Cu}>\mathrm{Pb}>\mathrm{Zn}>\mathrm{Cr}$ & 83 & 97 & 97 & 95 & 96 \\
\hline
\end{tabular}

*: removal efficiency $=(\mathrm{Ci}-\mathrm{Cf}) / \mathrm{Ci} \times 100 \%$

Table 4 Optimal pH for absorption of heavy metals on volcanic tuff.

\begin{tabular}{|c|c|c|}
\hline $\begin{array}{l}\text { Heavy } \\
\text { Metal ions }\end{array}$ & $\begin{array}{l}\text { Initial Conc. (Ci) } \\
\qquad(\mathrm{mg} / \mathrm{L})\end{array}$ & $\begin{array}{l}\text { Optimal pH for adsorption/ } \\
\text { absorption }\end{array}$ \\
\hline & 1 & $4>6>7>2$ \\
\hline \multirow[t]{3}{*}{$\mathrm{Cr}$} & 5 & $4>6>7>2$ \\
\hline & 10 & $4=6=7>2$ \\
\hline & 1 & $7>6>4>2$ \\
\hline \multirow[t]{3}{*}{$\mathrm{Zn}$} & 5 & $4=6>2>7$ \\
\hline & 10 & $6=7>4>2$ \\
\hline & 1 & $4=6>7>2$ \\
\hline \multirow[t]{3}{*}{$\mathrm{Cu}$} & 5 & $4=6=7>>2$ \\
\hline & 10 & $4+6=7>2$ \\
\hline & 1 & $6>7>2>4$ \\
\hline \multirow[t]{3}{*}{$\mathrm{Fe}$} & 5 & $6=7=4>2$ \\
\hline & 7 & $2=4=6=7$ \\
\hline & 1 & $4>2>6=7$ \\
\hline \multirow[t]{2}{*}{$\mathrm{Pb}$} & 5 & $4>2>6>7$ \\
\hline & 10 & $7>2=4>6$ \\
\hline
\end{tabular}

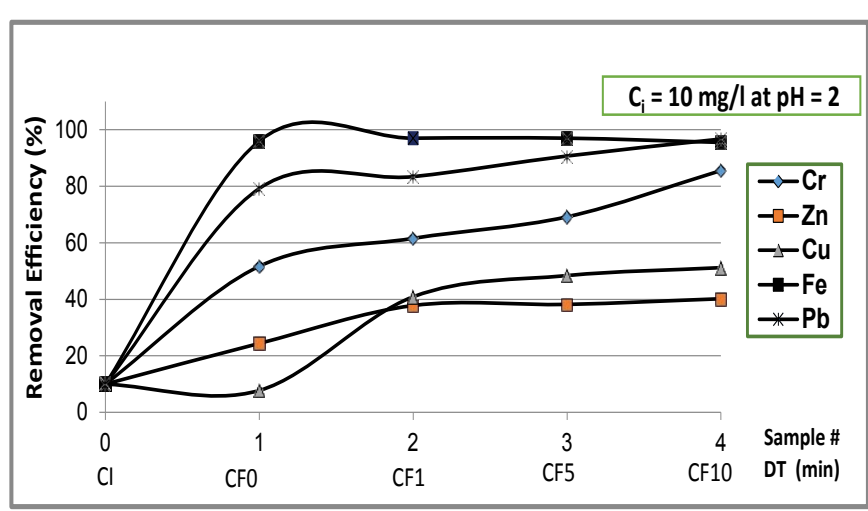

Figure 4 Removal efficiency of heavy metals in relation to initial solute concentration and contact time.

\section{Effect of contact time}

The effect of contact time on the removal efficiency of different heavy metals copper, zinc, chromium, iron and lead ions was studied under consideration of the ambient acidic condition (prevailing $\mathrm{pH}$ ).

Figures 3 and $\mathbf{5}$ describe the uptake of applied metal ions on the tuff material at varying contact time between absorbate and absorbent, while the $\mathrm{pH}$ is hold constant. The rate of uptake of metal ions was quite rapid for all ions as soon as a contact between tuff grains and ions solution occurs; the metal removal in the first run (zero contact time, $\mathrm{pH}=4$ ) ranges from $65-90 \%$ when ions pass through tuff bed with an initial concentration of $5 \mathrm{mg} / \mathrm{L}$. For iron, copper and zinc $90 \%$ of the ions are removed immediately as ions came in contact with tuff bed, while for chromium and lead 10 min contact time was required for an $82 \%$ and $87 \%$ removal, respectively (Figure 3 ). At $\mathrm{pH}=6$, the uptake of cupper on tuff grains occurred rapidly followed by iron when the solution passed through with an initial concentration of $1 \mathrm{mg} / \mathrm{L}$ (Figure 5). It has been observed that a change in $\mathrm{pH}$ results an immediate change of the order of removal of metals.

This is in agreement with the results obtained by Inglezakis et al. [44] for removal of heavy metals using orange peel activated carbon, Zamzow et al. [45] for remediation of chromium rich waters and wastewaters by fly ash. These results suggest that the adsorption capacity increases with the increase of concentration up to a limit. This fact indicates that if the metal ion concentration in solution increases, the difference in concentration between bulk solution and surface also increases, intensifying the mass transfer processes [46].

\section{Effect of initial concentrations}

Results obtained from both column and batch technique confirmed that natural occurring volcanic tuff can remove heavy metal ions with high performance when applied at different concentrations ranged between 1 to $20 \mathrm{mg} / \mathrm{L}$ at varying acidic conditions as illustrated in Table 3.

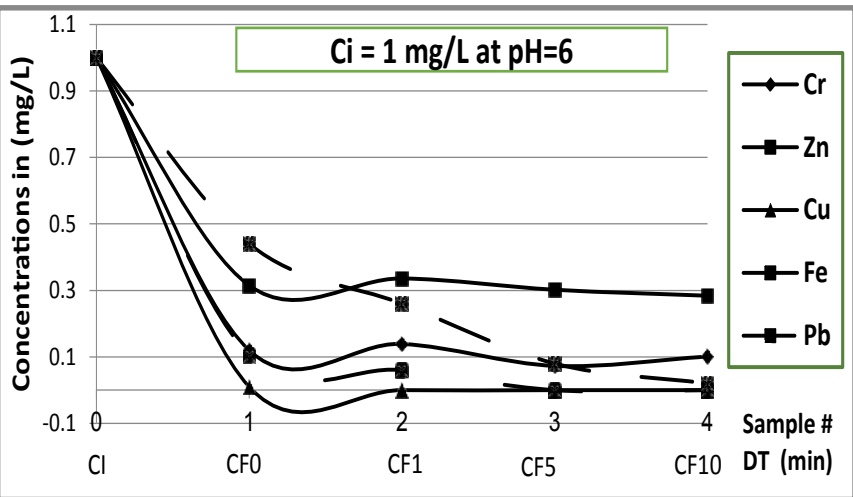

Figure 5 Effect of contact time on the removal of heavy metals on volcanic tuff grains. 
In general it can be observed that for some metal ions, the adsorption increases with increasing initial metal concentration, but under certain acidic conditions, and that leads to an increase in the amount of heavy metal ion adsorbed on to tuff grains. Whilst for other metals the adsorption decreases with increasing initial concentrations which emphasizes that the acidic condition is controlling the process. These results may be simply explained on the basis that the increase in the number of ions competing for the available binding spaces and also because of the lack of active sites on the absorbent at higher concentrations. Therefore, more metal ions were left in solution at higher levels of concentrations.

Figure 6 shows clearly that $\mathrm{pH}$ influence the process of absorption of $\mathrm{Cr}^{+6}$ on tuff material. At $\mathrm{pH}=2$ the ability of tuff material to absorb Chromium ions is low.

\section{Uptake capacity of volcanic tuff on metal ions}

In equilibrium, a certain relationship prevails between solute concentration in solution and adsorbed state (i.e., the amount of solute adsorbed per unit mass of adsorbent). Their equilibrium concentrations are a function of temperature. Therefore, the adsorption equilibrium relationship at a given temperature is referred as adsorption isotherm.

The amount adsorbed (qe) was calculated from the formula:

$\mathrm{qe}=\mathrm{V}(\mathrm{Ci}-\mathrm{Ce}) / \mathrm{m}$

where,

$C_{i}$ and $C_{e}$ are the initial and equilibrium liquid-phase concentrations $(\mathrm{mg} / \mathrm{L})$ of adsorbates; $V$ is the volume of the solution $(\mathrm{mL})$; and $m$ is the mass of adsorbent $(\mathrm{g})$. This equation assumes that the change in volume of the bulk liquid phase is negligible as the solute concentration is small and the volume occupied by the adsorbent is also small. The amount of heavy metals adsorbed on the sample was calculated using a previously determined calibration curve.

The experimental results of the binding of the heavy metals $\left(\mathrm{Cu}^{+2}, \mathrm{~Pb}^{2+}, \mathrm{Cr}^{2+}, \mathrm{Fe}^{2+}\right.$ and $\left.\mathrm{Zn}^{2+}\right)$ ions on natural volcanic tuff indicate a higher degree of ion removal at (lower/higher) initial concentration area of metal ions.

The plot in Figure 7 shows the uptake degree of each heavy metal ion as a function of the initial concentration and the prevailing acidic condition. The uptake degree is defined as:

$\alpha=(\mathrm{Ci}-\mathrm{Ce})$ wt $[\mathrm{mg} / \mathrm{l} . \mathrm{g}]$

$C_{i}$ being the initial concentration and $C_{e}$ final concentration of the particular ion, wt is the weight of tuff $(g) . \alpha$ : uptake degree relates the decrease in concentration to the $w t$ of absorbent. The analysis of obtained data shows the uptake of heavy metals depends mainly on: $\mathrm{pH}$, initial concentration, contact time and which element is being absorbed.

Figure 7 indicates that the volcanic bed behaves differently in respect to individual heavy metals is quite different. Each gram of the volcanic bed absorbed different amounts of heavy metals on selective basis and the velocity of uptake depends mainly on which heavy metal is being absorbed. At $\mathrm{pH}=4$, the absorption of chromium and iron is almost completed during the first minute of contact time in solid-liquid phase, while for zinc, lead and copper, the uptake process takes almost $10 \mathrm{~min}$ to be completed.

For comparison purposes, Figure 8 for instance, shows the uptake of applied heavy metal ions on material tuff at $\mathrm{pH}=6$. Under these circumstances, absorbent exhibits great affinity to absorb copper followed by iron and chromium. Another proves that prevailing acidic conditions have great role on controlling the absorption/ adsorption process.

In similar studies the use of natural and modified zeolites has been further investigated for the simultaneous removal of $\mathrm{Fe}^{+2}$ and $\mathrm{Mn}^{+2}$ from underground water samples. In particular, $\mathrm{Fe}^{+2}$ and $\mathrm{Mn}^{+2}$ removal levels were suggested to be between $22-90 \%$ and $61-100 \%$ for natural zeolite - clinoptilolite [42].

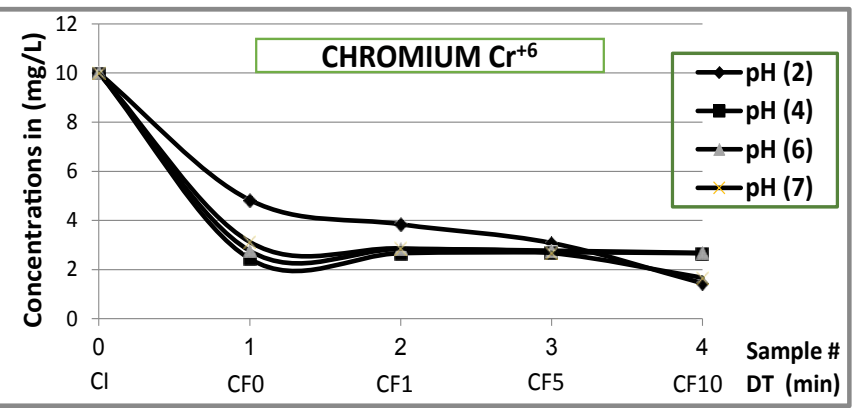

Figure 6 Removal of chromium $\mathrm{Cr}^{+6}$ from aqueous solution in association with contact time and $\mathrm{pH}$ value.

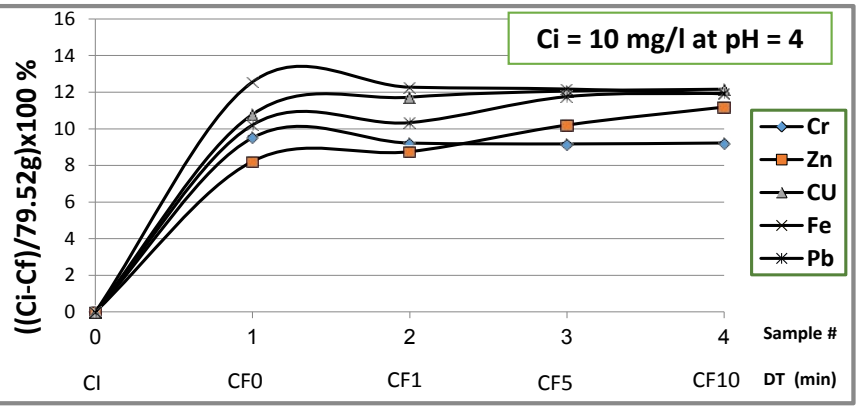

Figure 7 Uptake capacities of heavy metals in relation to initial solute concentration and contact time.

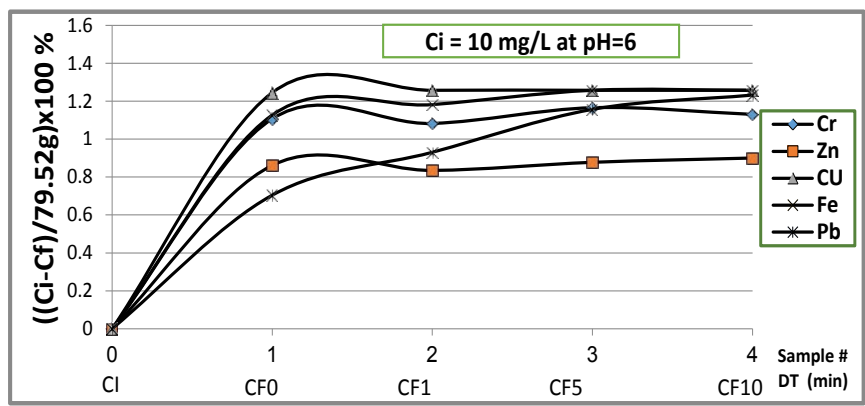

Figure 8 Uptake capacities of heavy metals in relation to initial solute concentration and contact time. 


\section{Breakthrough curves}

Based on the fact that in equilibrium, a certain relationship exists between solute concentration in solution and the amount of solute adsorbed per unit mass of adsorbent. This equilibrium state depends on many factors such as, temperature, $\mathrm{pH}$ amount of absorbent and the initial concentration of solute. To examine the uptake capacity of absorbent (saturation state), two metals iron (Fe) and copper ( $\mathrm{Cu}$ ) are applied to a fixed bed column filled with $10 \mathrm{~g}$ of volcanic tuff in order to examine the time for reaching saturation of material with these two metal ions and the total amount absorbed. These two metals were selected based on absorption results presented in Tables 3 and 4. Analysis results suggested that both metal ions experience $100 \%$ uptake by volcanic bed at $\mathrm{pH}=6$ and after 10 min contact time.

The batch adsorption experiment were conducted (started first with iron solution) with an initial concentration of $10 \mathrm{mg} / \mathrm{l} .40$ $\mathrm{ml}$ of this solution is applied to the column containing $10 \mathrm{~g}$ of bed material every $10 \mathrm{~min}$. The small aliquots of samples were withdrawn from the reaction and analyzed.

After exactly $335 \mathrm{~min}$ the analysis of the samples shows that the final concentration of iron in samples is still low, which means that the adsorption capacity of material is maintained high? In order to accelerate the saturation of the bed material, the experiment is then continued with an initial concentration of iron $=20 \mathrm{mg} / \mathrm{l}$, also here with 10 minutes tact. After exactly 570 min the final concentration stabilizes and starts to increase to a final concentration very close to feed concentration, this gives indication that the material is saturated with iron ions and reaches its ultimate absorbing capacity.

It is to emphasize that iron is selected with the believe that because iron is a major component of the natural material and the absorbing capacity of the material for iron can be limited when compared to the absorbing capacity of tuff on other metal ions that are less present.

The experiment is repeated for copper solution with an initial concentration of $10 \mathrm{mg} / \mathrm{l}$ using the same bed that is previously brought to saturation with iron ions. It is to observe that after exactly $192 \mathrm{~min}$ the material is completely saturated with copper ions.

\section{Uptake capacity factor for Iron and copper}

The Uptake capacity, UC, to absorb contaminants in this case metal ions, can be determined by using following mass balance equation:

$U C=(V / m) \times\left(C_{i}-C_{f}\right)$

Where:

$U C=$ Contaminant loading at a given time period until saturation point $(\mathrm{mg} / \mathrm{g})$

$V=$ Solution volume $(\mathrm{mL})$

$m=$ Mass of the adsorbent material (g)
$C_{i}=$ Solute initial concentration in solution $(\mathrm{mg} / \mathrm{L})$

$C_{f}=$ Solute final concentration in solution $(\mathrm{mg} / \mathrm{L})$

In this study, the iron uptake capacity and the breakthrough curve experiment was conducted and involves the application of 35 batch runs, $40 \mathrm{~mL}$ for each run with an initial concentration of $10 \mathrm{mg} / \mathrm{L}$. In addition, there are 24 applications each $40 \mathrm{~mL}$ of solution with an initial concentration of $20 \mathrm{mg} / \mathrm{L}$ following the first batch. This iron loading is completely absorbed by the 79.52 $\mathrm{g}$ bed material until reaching the saturation point. An uptake capacity factor can be calculated using these data as follows:

Iron loading: $35 \times 0.040 \mathrm{~L} \times \sum(\mathrm{Ci}-\mathrm{Cf}) \mathrm{mg} / \mathrm{L}+24 \times 0.040 \mathrm{~L} \times \sum(\mathrm{Ci}-\mathrm{Cf})$ $\mathrm{mg} / \mathrm{L}=17.24 \mathrm{mg}$

Uptake capacity factor, $\mathrm{UC}_{\mathrm{Fe}}=17.24 / 79.52 \mathrm{~g}=0.217 \mathrm{mg} \mathrm{Fe} / \mathrm{g}$ tuff.

For copper and in order to reach the saturation point with copper, there are 30 applications with initial concentration=10 $\mathrm{mg} / \mathrm{L}$ needed.

Copper loading: $30 \times 0.04 \mathrm{~L} \times \sum(\mathrm{Ci}-\mathrm{Cf}) \mathrm{mg} / \mathrm{L}=8 \mathrm{mg}$.

Uptake capacity factor, $\mathrm{UC}_{\mathrm{Cu}}=8.0 \mathrm{mg} / 79.52 \mathrm{~g}=0.10 \mathrm{mg} \mathrm{Cu} / \mathrm{g}$ tuff.

Accordingly, the maximum absorption capacities for volcanic tuff were found as $0.217 \mathrm{mg} \mathrm{Fe} / \mathrm{g}$ tuff and $0.100 \mathrm{mg} \mathrm{Cu} / \mathrm{g}$ tuff. An uptake ratio of iron uptake capacity and copper uptake capacity can be determined as $\mathrm{UC}_{\mathrm{Fe}} / \mathrm{UC}_{\mathrm{Cu}}=2.17$. This result indicates that volcanic tuff is capable to absorb more iron rather than copper. Similar studies also confirm these results [47]. For copper uptake capacity, a study Kannan and Rengasamy [48] reported comparative results.

This experiment confirms that the uptake of iron ions $\mathrm{Fe}^{+3}(\mathrm{mg}$ $\mathrm{Fe}^{+3} / \mathrm{g}$ tuff) by tuff material declines gradually with time as more solution is added until a saturation (equilibrium) state is achieved. A correlation curve in Figure $\mathbf{9}$ demonstrates the association of declining uptake capacity with advancing time until saturation. Similar trend shows the uptake behavior of tuff material in regard to copper $\left(\mathrm{Cu}^{+2}\right)$.

\section{Sorption isotherm models}

The term sorption is generally involves expressions, absorption and adsorption. Adsorption is mostly estimated using the equation:

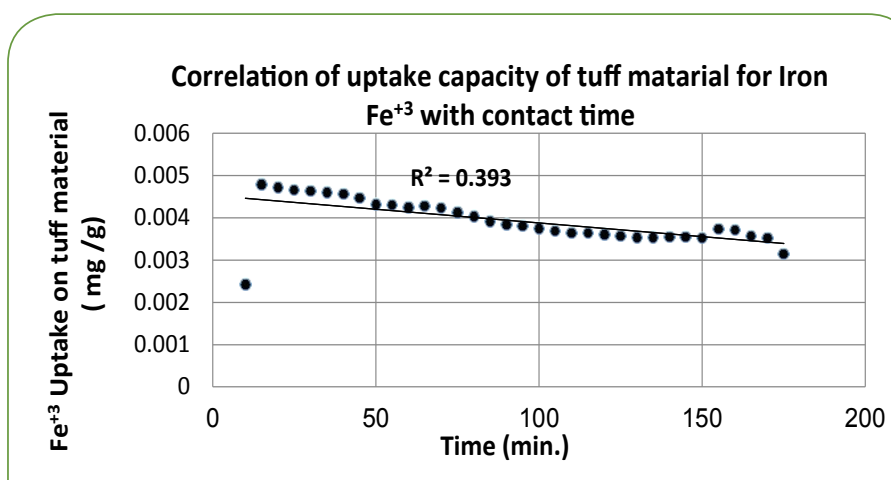

Figure 9 Correlation of uptake of iron ions on tuff material and contact time. 


\section{$\%$ Adsorption $\left.=\left(C_{i}-C_{f}\right) / C_{i}\right) \times 100 \%$}

Where $C_{i}$ and $C f$ are the concentrations of the metal ion in initial and final solution, respectively $[28,49]$. Equilibrium studies that give the capacity of the adsorbent and adsorbate are described by adsorption isotherms, which is usually the ratio between the quantity adsorbed and the remaining in solution at fixed temperature at equilibrium [50-52].

Several isotherm models are available to describe this equilibrium sorption distribution. Two of these isotherm equations were adopted in this study, as follows.

The Langmuir equation is used to estimate the maximum adsorption capacity corresponding to complete monolayer coverage on the adsorbent surface and is expressed by:

$q e=\left(q_{\max } K L C e\right) /(1+K L C e)$

where $K L\left(\mathrm{dm}^{3} \mathrm{~g}^{-1}\right)$ is a constant related to the adsorption/ desorption energy and $\mathrm{q}_{\max }$ is the maximum sorption upon complete saturation of the biomass surface [53]. The linearized form of the above equation after rearrangement is given by:

$\mathrm{Ce} / \mathrm{qe}=1 / q_{\max } K L+\mathrm{Ce} / q_{\max }$

The experimental data is then fitted into the above equation for linearization by plotting $\mathrm{Ce} / \mathrm{qe}$ against $\mathrm{Ce}$.

\section{Freundlich isotherm equation}

The Freundlich sorption isotherm, one of the most widely used mathematical descriptions, gives an expression encompassing the surface heterogeneity and the exponential distribution of active sites and their energies. The Freundlich isotherm is defined as:

$q e=K C e^{1 / n}$ and in linearized form is:

$\log q e=\log k+1 / n \log C e$

Where, $\mathrm{Ce}$ is the equilibrium concentration in $\mathrm{mg} / \mathrm{l}, q e=$ amount of adsorbate adsorbed per unit weight of adsorbent $(\mathrm{mg} / \mathrm{g})$. $k$ is a parameter related to the temperature and " $n$ " is a characteristic constant for the adsorption system under study.

\section{Adsorption experiments}

After each adsorption, the residual metal ions of $(\mathrm{Cr}, \mathrm{Zi}, \mathrm{Fe}, \mathrm{Cu}$ and $\mathrm{Pb}$ ) were determined using following equations:

$\%$ Adsorption $\left.=\left(C_{i}-C_{f}\right) / C_{i}\right) \times 100 \%$

$X / M=V\left(C_{i}-C_{f}\right) / m$

Where: $V=$ Volume of solute $(\mathrm{mL}), M=$ Mass of adsorbent $(\mathrm{mg})$, $\mathrm{Ci}=$ Initial concentration $(\mathrm{mg} / \mathrm{L}), \mathrm{Ce}=$ Final metal concentration at equilibrium ( $\mathrm{mg} / \mathrm{L}), \mathrm{X}=$ Adsorbate concentration/adsorption capacity of tuff material $(\mathrm{mg} / \mathrm{g})$.

Five mixed solutions with concentrations $25 \mathrm{mg} / \mathrm{L}, 50 \mathrm{mg} / \mathrm{L}$, $75 \mathrm{mg} / \mathrm{L}, 100 \mathrm{mg} / \mathrm{L}$ and $125 \mathrm{mg} / \mathrm{L}$ of Fe and Cu were made by proper dilution of stock solution for both metals. The $\mathrm{pH}$ was adjusted and maintained at 6 throughout the experiment. $25 \mathrm{~mL}$ of the prepared samples was poured into five flasks. $10 \mathrm{~g}$ of the adsorbent was introduced to each flask and was agitated for 1.25 h. Thereafter the concentrations of Fe and Cu were determined.

The equilibrium data obtained from this experiment were observed to fit with Langmuir and Freundlich isotherm models. Plotting $\mathrm{Ce} /(\mathrm{x} / \mathrm{m})$ against Ce for both metals as shown in Figures 10 and 11 indicates that the equilibrium data follows the Langmuir model.

Langmuir parameters and correlation coefficient square $\mathrm{R}^{2}$ are presented

The essential characteristics of the Langmuir isotherm can be expressed in terms of a dimensionless constant separation factor ( $R L$ ) which is defined by $R L=1 /(1+K L$ Ce). Where $R L$ is Langmuir constant, $\mathrm{Ce}$ is the highest final concentration $(\mathrm{mg} / \mathrm{L})$. The value of $R L$ suggests the type of the isotherm to be either unfavorable (as $R L>1$ ), linear $R L=1$, favorable $0<R L<1$ or may be irreversible if $R L=0$ [54]. In this case, Langmuir isotherm is favorable as $\mathrm{RL}=0.966$ and 0.944 for $\mathrm{Fe}^{+3}$ and $\mathrm{Cu}^{+2}$, respectively as shown in Figures 12 and 13.

The correlation between $\log x / m$ and $\log C e$ are presented in Figure 12 and the adsorption of iron ions onto the adsorbent gave a straight line; values of " $n$ " between 2 and 10 show good adsorption.

The kinetic studies of adsorption of heavy metals $\mathrm{Fe}^{+3}$ and $\mathrm{Cu}^{+2}$ ions onto volcanic tuff material was carried out using the second order models, the Freundlich isotherm constants and their correlation coefficients $\mathrm{R}^{2}$ are listed in Table 5.

The calculations presented in Table $\mathbf{5}$ which are derived from Figures 10-13 indicate that the absorption process in following

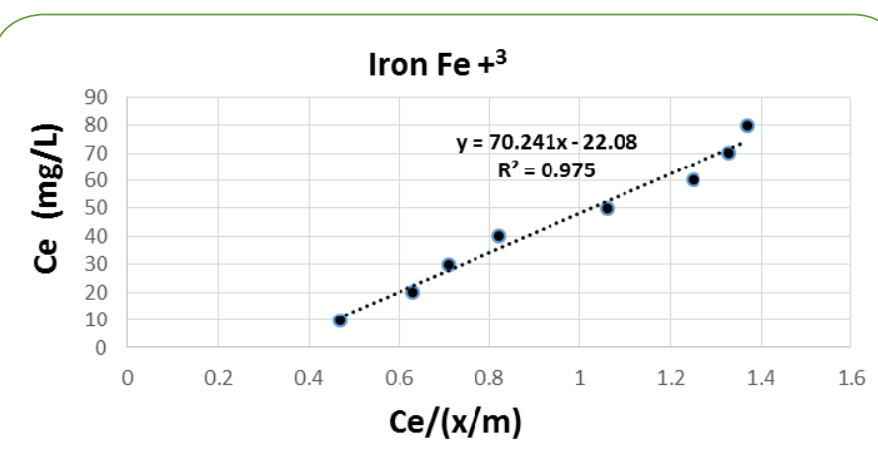

Figure 10 Removal of iron ions $\mathrm{Fe}^{+3}$ by volcanic tuff at $\mathrm{pH}=6$ fitted to Langmuir isotherm.

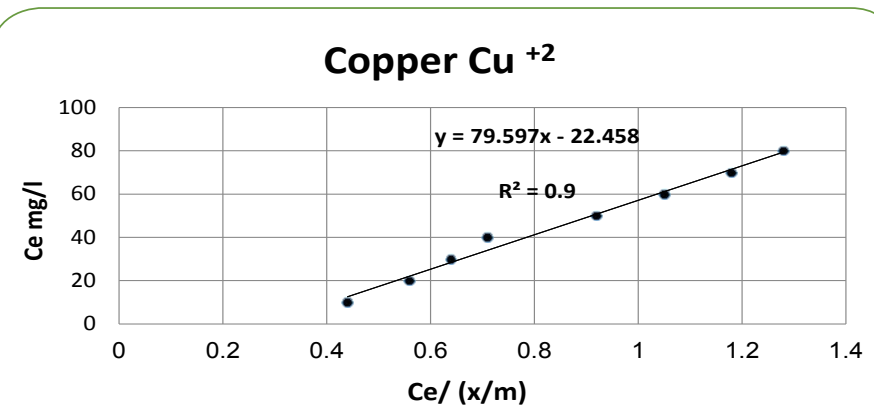

Figure 11 Removal of copper ions $\mathrm{Cu}^{+2}$ by volcanic tuff at $\mathrm{pH}=6$ fitted to Langmuir isotherm. 
Langmuir and Frundlich isotherms with high certainty.

Comparative results are reported by Karnib et al. [55].

Relating absorbed concentrations of $\mathrm{Cr}^{+6}$ and $\mathrm{Zi}^{+2}$ to their

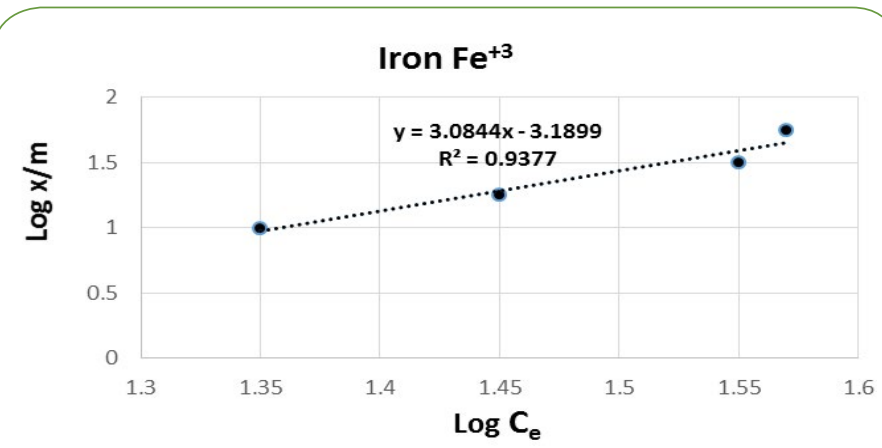

Figure 12 Removal of iron ions $\mathrm{Fe}^{+3}$ by volcanic tuff at $\mathrm{pH}=6$ fitted to Freundlich isotherm.

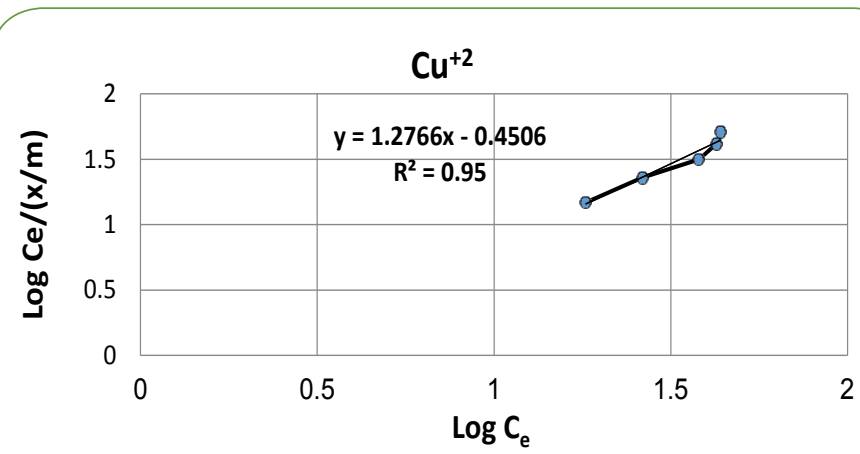

Figure 13 Removal of iron ions $\mathrm{Cu}^{+2}$ by volcanic tuff at $\mathrm{pH}=6$ fitted to Freundlich isotherm.

Table 5 Values for Langmuir and Freundlich adsorption models.

\begin{tabular}{|c|c|c|}
\hline Best-fit isotherm models & $\mathrm{Fe}^{+3}$ & $\mathrm{Cu}^{+2}$ \\
\hline $\begin{array}{l}\text { Langmuir model } \\
\text { Plot }(\mathrm{Ce} / \mathrm{x} / \mathrm{m}) \text { vs. Ce } \\
\text { Correlation coefficient } \\
\text { Regression equation }\end{array}$ & $\begin{array}{c}R^{2}=0.975 \\
y=70.241 x-22.08 \\
1 / n=0.51, k=6.39\end{array}$ & $\begin{array}{c}R^{2}=0.9874 \\
y=79.597 x-22.458 \\
1 / n=0.51, k=5.89\end{array}$ \\
\hline $\begin{array}{l}\text { Langmuir model } \\
\text { Plot Log } \mathrm{Ce} / \mathrm{x} / \mathrm{m} \text { vs. log Ce } \\
\text { Correlation coefficient } \\
\text { Regression equation }\end{array}$ & $\begin{array}{c}R^{2}=0.9399 \\
y=3.0844 x-3.1899 \\
q_{\max }=63.76(\mathrm{mg} / \mathrm{g}) \\
b=0.42(1 / \mathrm{mg})\end{array}$ & $\begin{array}{c}R^{2}=0.95 \\
y=1.2766 x-0.4506 \\
q_{\max }=68.46(\mathrm{mg} / \mathrm{g}) \\
b=0.42(1 / \mathrm{mg})\end{array}$ \\
\hline
\end{tabular}

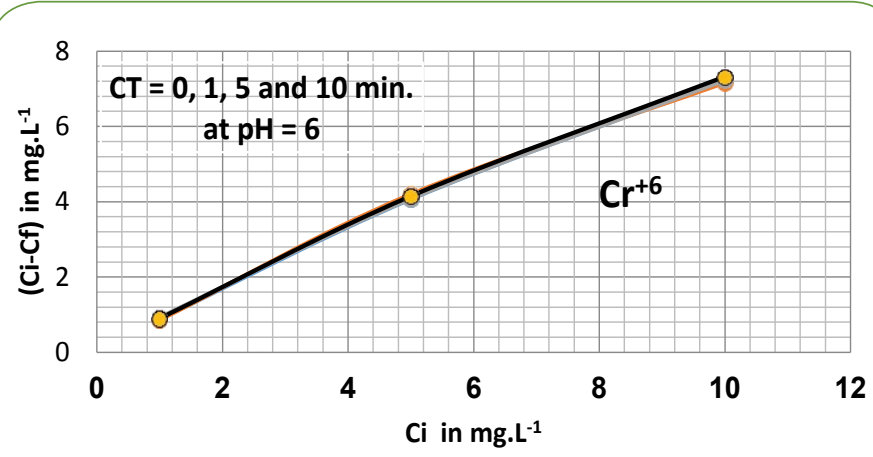

Figure 14 Removal of chromium ions $\mathrm{Cr}^{+6}$ by volcanic tuff at $\mathrm{pH}=6$ fitted to Freundlich isotherm.

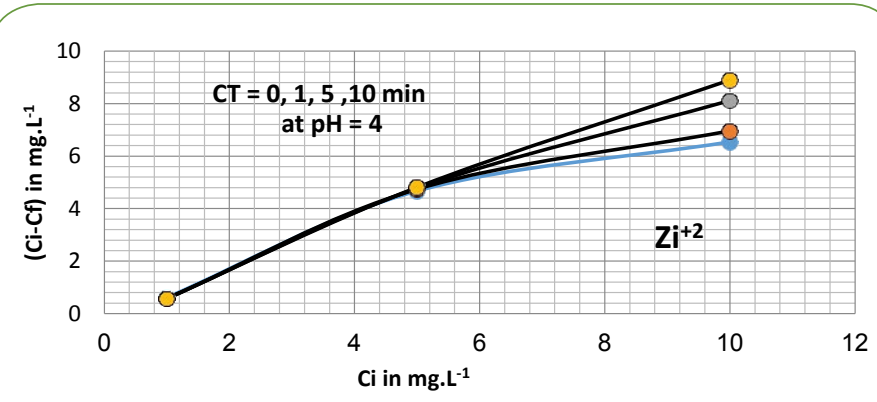

Figure 15 Removal of zinc ions $\mathrm{Zi}^{+6}$ by volcanic tuff at $\mathrm{pH}=6$ fitted to Freundlich isotherm.

applied initial concentrations as presented in Figures 14 and 15 emphasizes the hypothesis that the absorption process of chromium and zinc ions also best fit to Langmuir and Freundlich isotherms.

\section{Conclusion}

On controlling and optimizing all the conditions studied in this work, it was confirmed that untreated natural volcanic tuff is an effective and inexpensive absorbent for the removal of $\mathrm{Cr}^{+6}, \mathrm{Fe}^{+2}$, $\mathrm{Cu}^{+2}, \mathrm{Zn}^{+2}$ and $\mathrm{Pb}^{+2}$ from contaminated pharmaceutical wastewater and although unknown, it can compete well with commercial adsorbents such as treated zeolite and activated carbon.

The column experiments provide useful information about the transport behavior of the heavy metal contaminants and the relevant parameters for effective removal are contact time, ambient $\mathrm{pH}$, initial concentration and temperature.

The sorption behavior of the used samples towards $\mathrm{Cr}^{+6}, \mathrm{Fe}^{+2}$, $\mathrm{Cu}^{+2}, \mathrm{Zn}^{+2}$ and $\mathrm{Pb}^{+2}$ indicated high initial rate of metal ions uptake. The percentage removal of ions found to be between $10-99 \%$ influenced mainly by ambient $\mathrm{pH}$. Most probably, acidic metal solutions reduce the performance of natural volcanic tuff in retarding the movement of heavy metals and affect the mineralogical composition of the materials.

The natural volcanic tuff possess good retention capacity for cationic metals showing metal uptake affinity For instance, when a solution containing two different metals is flowing through a fixed bed, the tuff material usually favors one ion over another. It showed that the selectivity sequence of metal ions by the adsorbents was dependent on the system employed, and was mainly influenced by the initial concentrations of the metal ions, but controlled also by the initial $\mathrm{pH}$ of the solution.

Obtained results showed that volcanic tuff has the greatest ability to remove $\mathrm{Pb}^{+2}$ at lower $\mathrm{pH}$ whereas at higher $\mathrm{pH}$ it favors the uptake of $\mathrm{Fe}$ and $\mathrm{Cu}$ ions. Obtained correlation coefficients $\mathrm{R}^{2}>0.94$ suggested high fitting of the experimental data to Langmuir isotherm and Freundlich isotherm for both $\mathrm{Cu}$ and $\mathrm{Fe}$ ions. Results also confirm that the uptake of chromium and zinc ions best fit to Langmuir and Freundlich isotherm regimes.

Breakthrough curves for iron and copper shows that the uptake capacity of iron per gram of tuff material equals $0.217 \mathrm{mg} \mathrm{Fe} \mathrm{e}^{+2} / \mathrm{g}$ tuff, while the uptake capacity for copper equals $0.1 \mathrm{mg} \mathrm{Cu} / \mathrm{g}$ tuff, suggesting the high ability of tuff material to eliminate iron rather than copper from aqueous solutions. 


\section{References}

1 Konstantinos D, Achilleas C, Valsamidou V (2011) Removal of nickel, copper, zinc and chromium from synthetic and industrial wastewater by electrocoagulation. Int J Environ Sci 1: 698-703.

2 Inglezakis VJ, Loizidou, Grigoropoulou (2003) Ion exchange of Pb2+, $\mathrm{Cu}^{2+}, \mathrm{Fe}^{2+}$, and $\mathrm{Cr}^{2+}$ on natural clinoptilolite: Selectivity determination and influence of acidity on metal uptake. J Colloid Interface Sci 261 49-54.

3 Tchounwou PB, Yedjou CG, Patlolla AK, Sutton DJ (2012) Heavy metals toxicity and the environment. EXS 101: 133-164.

4 Dorne JL, Kass GE, Bordajandi LR, Amzal B, Bertelsen U (2011) Human risk assessment of heavy metals: Principles and applications. Met Ions Life Sci 8: 27-60.

5 Rzymski P, Tomczyk K, Rzymski P, Poniedziałek B, Opala T, et al. (2015) Impact of heavy metals on the female reproductive system. Environ Med 22: 259-264.

6 Nunez O, Fernandez NP, Martin MI, Bel LA, Locutura JF (2016) Association between heavy metal and metalloid levels in topsoil and cancer mortality in Spain. Environ Sci Pollut Res Int 24: 7413-7421.

7 Stern BR (2010) Essentiality and toxicity in copper health risk assessment: Overview, update and regulatory considerations. J Toxicol Environ Health A 73: 114-127.

8 Anyakora C, Kenneth NK, Awodele O, Nwadike C, Arbabi M, et al. (2011) Concentrations of heavy metals in some pharmaceutical effluents in Lagos, Nigeria. J Environ Chem Ecotoxicol 3: 25-31.

9 Khan S, Cao Q, Zheng YM, Huang YZ, Zhu YG (2008) Health risks of heavy metals in contaminated soil and food crop irrigated with wastewater in Beijing, China. Environ Pollut 152: 686-692.

10 Hernandoa MD, Mezcuaa M, Fernández-Albaa AR, Barcelób D (2006) Environmental risk assessment of pharmaceutical residues in wastewater effluents, surface waters and sediments. Talanta 69: 334-342.

11 Arnold KE, Ross BA, Ankley GT, Sumpter JP (2014) Medicating the environment: assessing risks of pharmaceuticals to wildlife and ecosystems. Philos Trans R Soc Lond B Biol Sci 369: 1656.

12 Osaigbovo AE, Orhue ER (2006) Influence of pharmaceutical effluent on some soil chemical properties and early growth of maize (Zea mays L). Afr J Biotechnol 5: 1612-1617.

13 Meena AK, Kadirvelu K, Mishra GK, Rajagopal C, Nagar PN (2008) Adsorptive removal of heavy metals from aqueous solution by treated sawdust (Acacia arabica). J Hazard Mater 150: 604-611.

14 Roberts PH, Thomas KV (2006) The occurrence of selected pharmaceuticals in wastewater effluent and surface waters of the lower Tyne catchment. Sci Total Environ 356: 143-153.

15 Verlicchia P, Al Aukidya M, Zambelloa E (2012) Occurrence of pharmaceutical compounds in urban wastewater: Removal, mass load and environmental risk after a secondary treatment $-\mathrm{A}$ review. Sci Total Environ 429: 123-155.

16 Idris MA, Kolo BG, Garba ST, Waziri I (2013) Pharmaceutical industrial effluent: Heavy metal contamination of surface water in Minna, Niger State, Nigeria. Bull Env Pharmacol Life Sci 2: 40-44.

17 Bulinski R, Bloniarz J, Libelt J (2009) Presence of some trace elements in polish food products. XV. Contents of lead, copper, cadmium, nickel, chromium, zinc, cobalt, manganese, copper and iron in some milk products. Bromatologia i Chemia Toks 26: 23-27.
18 Ashfaqa M, Khujasta NK, Saif Ur Rehman M, Mustafaa G, Faizan MN, et al. (2017) Ecological risk assessment of pharmaceuticals in the receiving environment of pharmaceutical wastewater in Pakistan. Ecotoxicol Environ Saf 136: 31-39.

19 Panayotova M, Velikov B (2003) Influence of zeolite transformation in a homoionic form on the removal of some heavy metal ions from wastewater. J Environ Sci Health A Toxic Hazard Subst Environ Eng 38: 545-554.

20 Amarasinghe BMWPK, Williams RA (2007) Tea waste as a low cost adsorbent for the removal of $\mathrm{Cu}$ and $\mathrm{Pb}$ from wastewater. Chem Eng J 132: 299-309.

21 Babel S, Kurniawan TA (2003) Low-cost adsorbents for heavy metals uptake from contaminated water: A review. J Hazard Mater 97: 219-243.

22 Inglezakis VJ, Poulopoulos S (2006) Adsorption, Ion Exchange and Catalysis, first edition, Inglezakis VJ. Design of Operations and Environmental Applications, Elsevier Science Limited, pp: 31-50.

23 Ziyath M, Mahbub P, Goonetilleke A, Adebajo M, Kokot S, et al. (2011) Influence of physical and chemical parameters on the treatment of heavy metals in polluted stormwater using zeolite - A review. JWARP 3: 10.

24 Ali AAH, El-Bishtawi R (1997), Removal of lead and nickel ions using zeolite tuff. J Chem Technol Biotechnol 69: 27-34.

25 Erdem E, Karapinar N, Donat R (2004) The removal of heavy metal cations by natural zeolites. J Colloid Interface Sci 280: 309-314.

26 Gadipelly C, Pérez-González A, Yadav GD, Ortiz I, Ibáñez R, et al. (2014) Pharmaceutical industry wastewater: Review of the technologies for water treatment and reuse. Ind Eng Chem Res 53: 11571-11592.

27 Caputo D, Pepe $F$ (2007) Experiments and data processing of ion exchange equilibria involving Italian natural zeolites: A review. Micropor Mesopor Mater 105: 222-231.

28 Fu F, Qi W (2011) Removal of heavy metal ions from wastewaters: A review. J Environ Manage 92: 407-418.

29 Wang S, Peng Y (2010) Natural zeolites as effective adsorbents in water and wastewater treatment. Chem Engin J 156: 11-24.

30 Margeta K, Vojnović B, Zabukovec LN (2011) Development of natural zeolites for their use in water-treatment systems. Recent Pat Nanotechnol 5: 89-99.

31 Barakat MA (2011) New trends in removing heavy metals from industrial wastewater. Arabian Journal of Chemistry 4: 361-377.

32 Stylianou MA, Kollia D, Haralambous KJ, Inglezakis VJ, Moustakas KG, et al. (2006) Effect of acid treatment on the removal of heavy metals from sewage sludge. Desalination 215: 73-81.

33 Chutia P, Kato S, Kojima T, Satokawa S (2009) Arsenic adsorption from aqueous solution on synthetic zeolites. J Hazard Mater 162 : 440-447.

34 Dimirkou A (2007) Uptake of $\mathrm{Zn} 2+$ ions by a fully ironexchanged clinoptilolite. Case study of heavily contaminated drinking water samples. Water Res 41: 2763-2773.

35 Hui KS, ChaoCY, Kot SC (2005) Removal of mixed heavy metal ions in wastewater by zeolite $4 \mathrm{~A}$ and residual products from recycled coal fly ash. J Hazard Mater 127: 89-101.

36 Trgo M, Peri' J (2003) Interaction of the zeolitic tuff with Zn containing simulated pollutant solutions. J Colloid Interface Sci 260: 166-175. 
37 Cho H, Oh D, Kim K (2005) A study on removal characteristics of heavy metals from aqueous solution by fly ash. J Hazard Mater 127: 187-195.

38 Esposito A, Pagnanelli F, Vegliò F (2002) pH-related equilibria models for biosorption in single metal systems. Chem Eng Sci 57: 307-313.

39 Abdel Salam OE, Reiad NA, ElShafei MM (2011) A study of the removal characteristics of heavy metals from wastewater by lowcost adsorbents. J Adv Res 2: 297-303.

40 Orodu VE, Olis de me, Okpu RC (2014) Removal of heavy metals from aqueous solutions using snail shell powder as a vailable adsorbent. IJST 3: 7.

41 Lisa N, Kanagaratnam B, Trever M (2004) Biosorption of Zinc from aqueous solutions using biosolids. Adv Env Res 8: 629-635.

42 Xiao F, Ju-Chang H (2009) Comparison of biosorbents with organic sorbents for removing copper (II) from aqueous solutions. J Environ Man 90: 3105-3109.

43 Olayinka KO, Oyedeji OA, Oyeyiola OA (2009) Removal of chromium and nickel ions from aqueous solution by adsorption on modified coconut husk. Afr J Environ Sci Tech 3: 286-293.

44 Inglezakis VJ, Doula MK, Aggelatou V, Zorpas AA (2010) Removal of iron and manganese from underground water by use of natural minerals in batch mode treatment. Desalin Water Treat 18: 341-346.

45 Zamzow MJ, Eichbaum BR, Sandgren KR, Shanks DE (1990) Removal of heavy metals and other cations from waste water using Zeolites. Sep Sci and Technol 25: 1555-1569.

46 Bernard E, Jimoh A (2013) Adsorption of Pb, Fe, Cu, and $\mathrm{Zn}$ from industrial electroplating wastewater by orange peel activated carbon. Int J Eng and Applied Sci 4: 2.
47 Sharma YC, Uma S, Upadhya SN, Weng CH (2008) Studies on an economically viable remediation of chromium rich waters and wastewaters by PTPS fly ash. Colloids Surf A Physicochem Eng Aspects 317: 222-228.

48 Kannan N, Rengasamy G (2005) Comparison of cadmium ion adsorption on various activated carbons. Water Air Soil Pollut 163: 185-201.

49 Boldizsar N, Mânzatu C, Măicăneanu A, Tudoran B, Majdik C, et al. (2017) Linear and non-linear regression analysis for heavy metals removal using Agaricus bisporus macrofungus. Arabian Journal of Chemistry 10: S3569-S3579.

50 Adaikalam S, Malairajan S (2015) Removal of $\mathrm{Cu}(\mathrm{II})$ ions from synthetic waste water by using a novel biocarbon. Elixir Appl Chem 78: 29654-29656

51 Hua M, Zhang S, Pan B, Zhang W, Lv L, et al (2012) Heavy metal removal from water/wastewater by nanosized metal oxides: A review. J Hazard Mater 211-212: 317-331.

52 Hashem MA (2007) Adsorption of lead ions from aqueous solution by okra wastes. Int J Phys Sci 2: 178-184.

53 Horsfall, MJ, Abia AA, Spiff Al (2006) Kinetic studies on the adsorption of $\mathrm{Cd}^{2+}, \mathrm{Cu}^{2+}$ and $\mathrm{Zn}^{2+}$ ions from aqueous solutions by cassava (Manihot esculenta) Tuber Bark Waste. J Bioresour Technol 97: 283-291.

54 Malik PK (2004) Dye removal from wastewater using activated carbon developed from sawdust. Adsorption equilibrium and kinetics. J Hazard Mater 113: 81-88.

55 Karnib M, Kabbani A, Hanafy H, Olama Z (2014) Heavy metals removal using activated carbon, silica and silica activated carbon composite. Energy Procedia 50: 113-120. 